\title{
Rousseau e AS LeIS Das Cotas PARA Negros NAS UnIVERSIDADES Públicas do Rio de JANEIRO ${ }^{1}$
}

\section{Ailton Benedito de Sousa $a^{2}$}

C'est précisément parce que la force des choses tend toujours a detruire l'egalité, que la force de la législation doit toujours tender à la maintenir

Com a questão das cotas - principalmente a celeuma e o teor dos argumentos para sua revogação ou descaracterização - a realidade social brasileira vem-se nos mostrar com toda sua nudez sem pudor, trazendo à cena o que se tem conseguido fingir que não se vê há quinhentos anos: realmente, formamos um ente social com heranças físicas e espirituais de natureza colonial e escravocrata, resultante de um concerto entre as forças colonizadoras européias contra ou sobre bandos de seres escravizados ou escravizáveis, hoje como há quinhentos anos, em desesperada luta por se constituírem num corpo político, a partir da assinatura de um pacto, qualquer que seja.

1 Precisamente, uma Lei e decretos. Quanto a essa, foi sancionada pelo Governador Anthony Garotinho em 9/11/ 2001, e institui cota de 40\% para as populações negra e parda no acesso à UERJ - Universidade do Estado do Rio de Janeiro, e a UENF - Universidade Estadual do Norte Fluminense (Lei n 3708 , publicada no DOERJ de11/ 11/2001). Quanto ao mais importante Decreto (o de 30/08/2001) que entre suas disposições "assegura a0s estudantes oriundos da rede pública (do Estado) o direito a concorrer a $50 \%$ das vagas dos cursos e turnos oferecidos pelas universidades públicas do Estado, obedecida a limitação de vagas existentes, a serem preenchidas de acordo com o critério da melhor nota". (Publicado no DOERJ de 3/09/2001). Observe-se que, por enquanto (2003), só as famílias muito pobres, em sua maioria negras, matriculam os filhos na rede pública de ensino primário e secundário. Com ambos os diplomas, tem-se um múltiplo contencioso num contexto absurdo em que $90 \%$ das vagas ficariam comprometidas, facilitando sua revogação, até mesmo pela argüição de sua inconstitucionalidade.

2 Professor do Centro Brasileiro de Estudos Latino-Americanos. Editor da revista Comunicação \& Política. 


\section{Nós e o Contrato Social}

"Embora nascido livre, em qualquer lugar o homem é visto sob ferros". Esta é a primeira constataçã̃o de Rousseau, com que elimina eventuais dúvidas quanto à sua metodologia e proposições de base: a) o pacto, construção virtual, hipótese estruturante, foi e é sempre desrespeitado pelos que detêm o poder; b) é abundante a produção teórica com vistas a justificar o quadro resultante desse desrespeito; c) a passagem do Estado de Natureza para o Estado Civil, então, torna-se a fonte da infelicidade dos homens; d) democracia - âmbito da Justiça - exige competição entre iguais. Já que a igualdade não existe naturalmente, cabe à Lei estabelecê-la (cf. a epígrafe); e) já que seria impossível a volta ao Estado de Natureza, e sendo igualmente impossível modificar o homem, cumpre modificar, no sentido de aperfeiçoar a sociedade, para o que o autor expõe à análise seu modelo teórico.

Amado ou detestado, dentre os clássicos do pensamento político contemporâneo Rousseau - um feixe ambulante de contradições, porque acima de tudo humano - éo mais didático, o de mais clara compreensão por parte dos especialistas e não especialistas, tanto pelo fundo contrastante em que projeta e realça suas idéias, quanto pelo poder de síntese manifestado por meio de um admirável domínio dos instrumentos da retórica. Nesse sentido, para uma melhor visualização da controversa questão das cotas para estudantes negros nas universidades do Estado do Rio de Janeiro, apoiemo-nos em Rousseau, não só com objetivos didáticos quanto à compreensão dos nossos impasses estruturais, mas também com o objetivo de impedir que aqueles que a priori postulam a inconstitucionalidade dessas leis apropriem-se dos argumentos desse autor, descaracterizando-os.

Que é a nação? - como representarmos a nós mesmos, que nos assumimos brasileiros, a gênese desta 'nação' oriunda das vagas colonizadoras do século XVI? Subconjuntos culturais intercomunicantes, que se reconhecem complementares em igualdade, em desigualdade, em evolução, no sentido de superar seus desequilibrios? Tem (deveria ter) natureza contratual ou fática, é do jeito em que se encontra? Está em transformação? Para quê? Para onde?

Como se forma uma nação? - eis outra questão. De acordo com o modelo teórico de Jean-Jacques Rousseau, quer em 1822, com a Independência, quer em 1888 com a Abolição, quer em 1889 com a República, não conseguimos formar a nação, não nos qualificamos para assinar o Pacto, o Contrato Social. Entre outras, isto equivale a dizer que mesmo se um quarto da sociedade brasileira se diga hoje no 
âmbito da Soberania, da Cité ou da Cidadania, a verdade é que todos ainda temos seqüestradas em áridos rincões do estado de natureza hobbesiano partes essenciais de nosso ser individual e coletivo. A afirmação não implica desconhecer o permanente esforço da maioria do povo brasileiro pelo aperfeiçoamento de nossa experiência social. Com a Revolução de 30, por exemplo, se as classes médias tendo à frente os militares, não trouxeram à mesa segmentos populares, com sua diversidade étnica, para entabularem negociações visando ao Pacto, pelo menos unilateralmente, isto é, sem consulta, agiram como se a Nação fossem, criando suas bases mínimas, há duas décadas em processo de desfazimento pelos corifeus do neoliberalismo.

De modo diferente daqueles teóricos que, como Grotius, ou mesmo Aristóteles, vêem na força, no direito do mais forte, no direito à escravização do mais fraco, o fundamento das sociedades humanas, para Rousseau esse fundamento éa Vontade soberana de seres livres, vontade como expressão da razão, apanágio da Espécie. Na explicitação da gênese das sociedades humanas, Rousseau cita Grotius, até mesmo como fundo contrastante, "que teria dúvidas sobre se o gênero humano pertence a uma centena de homens", ou se uma centena de homens pertence ao gênero humano, tendendo esse autor do século XVII para a primeira formulação. Como se pode ver, no que tange a fatores sócio-políticos como cor, etnia, somos a corporificaçã̃o das idéias de Grotius.

Segundo Rousseau, homens livres vivendo em Estado de Natureza, detentores de uma imensa pauta de direitos que já lhes fora deferida, inscrita em suas consciências (o Direito Natural) alienam, isto é, doam todos esses direitos e bens a um Ente Coletivo, ou melhor, fundem-se num inédito Ente Coletivo, sob a condição de que aí ninguém terá nada mais que outrem, porque não terá dado nada a mais que outrem. Observe-se que se tal jamais pôde haver ocorrido na Europa, muito menos terá ocorrido aqui, tendo em vista o status de colônia, cujo perfil sintético apresenta: a) poucos servidores da empresa colonial, laicos ou religiosos, mas necessariamente escravocratas, vinculados a um projeto de dominação externa irrevogável; b) um estamento médio inexpressivo, moral e economicamente massacrado, ec) a imensa massa de escravos negros eíndios, que nem mesmo expectativa de vida terão. Observe-se que os servidores da empresa colonial têm a posse efetiva de tudo. ${ }^{3}$

3 J-J Rousseau. Du contrat social - extraits. Paris: Librairie Larousse, 1953.p.16. Após leitura deste artigo, observa Rodrigo Medeiros, professor da Universidade Gama Filho, "é importante frisar as distintas bases de organização do corpo político pelo menos nas Américas: sociedade baseada em pacto (Anglo-América); e sociedade baseada no "organicismo" (escravismo) (Ibero-América). Em um belo livro intitulado 0 espelbo de Próspero Richard Morse traça as diferenças, que têm origem no século XVII, da organização do corpo político nas Américas Anglo-América e Ibero-América — e revela as dificuldades de implantar o liberalismo político em países 
Com referência explícita à nossa herança escravocrata, permanentemente escamoteada até mesmo pela política do "apagar essa mancha vergonhosa de nossa história", lembre-se que para Rousseau direito e escravidão são termos que se excluem. Não pode haver contrato, encontro de vontades, expressão da razão, prerrogativa de homens, entre senhor escravo. Para escarnecer do absurdo de tal acordo, Rousseau fecha o capítulo com uma brincadeira perfeitamente legivel no âmbito da neolatinidade: "Je fais avec toi une convention toute à ta charge et toute à mon profit, que j'observerai tant qu'il me plaira, et que tu observeras tant qu'íl me plaira". ${ }^{4}$

Nada obstante os ensinamentos rouseaunianos, aqui não só se construiu um simulacro de nação tendo por base o trabalho escravo (a imensa maioria do povo fora do âmbito do direito) como se conseguiu perenizá-lo a partir de 1888, na medida em que se desfigura o que poderia ter sido a Abolição, com as chamadas políticas públicas vinculadas ao embranquecimento: o pavor da minoria branca de vir a constituir um país negro ou mestiço. Entre as ações de implementação imediata estará a arriscada opção de abrir o país à entrada de imigrantes não negros a partir da concessão de vantagens a novos e velhos imigrantes, até mesmo postos de trabalho que poderiam ter sido de ex-escravos.

Observe-se que nos momentos de intenso deslocamento populacional no mundo, ocorridos pouco antes ou após a República, o Brasil jamais foi opção de algum atrativo ao imigrante europeu, o país sempre ficando atrás dos Estados Unidos, Canadá, Austrália e Argentina. Em certo sentido, poder-se-ia dizer que 0 impulso modernizador deveria ter como motor a nossa qualificação para receber o imigrante europeu. Mas tudo aqui expelia 0 imigrante, da instituição servil às endemias urbanas e rurais. Daí o exagero na concessão de vantagens.

Da Independência até à Revolução de 30, por nada menos que cem anos, transferem-se essas políticas públicas do 'embranquecimento' para a competência das Províncias, depois tornadas Estados. Eserápara o imigrante que, num sentido ou noutro, se dará curso a uma série de políticas afirmativas: doação de terras (veja-se, em especial, o Triângulo Mineiro, ${ }^{5}$ sul do Estado de São Paulo e o Paranásó por registro), até mesmo

como o Brasil. No século XIX, os nossos liberais preferiram não se confrontar com os escravocratas e se dedicaram a formular leis, acreditando que estas gerariam efeitos moralizantes em nossa sociedade. Alguns aderiram ao liberalismo econômico e aproveitaram para legitimar, desta forma, a escravidão. Até o marxismo foi problemático entre nós, revela Morse". Cf. Morse, R. O espelbo de Próspero. São Paulo: Companhia das Letras, 1988.

4 J-J Rousseau. Op. cit., p. 23.

5 Essa região no Estado de Minas Gerais, de abundantes terras roxas, foi graciosamente dada a imigrantes síriolibaneses 'de direita' (exigência inegociável dos acordos de imigração), sob a promessa de que aqui viessem a plantar cítricos: É a origem do esteio econômico da família de muitas personalidades que, durante os 20 anos de ditadura, dominaram o nosso Ministério da Justiça. 
instalações de recepção para a família imigrante (a Ilhas das Flores), 'hotel' que para muitos seria uma 'prisão', adquire outros contornos quando em oposição ao descaso com que se tem tratado o povo negro e índio: favelas, mocambos, alagados, quilombos.

0 objetivo estratégico, jamais explicitado, de nossas secularmente aplicadas "políticas públicas de embranquecimento" é absurdo mesmo: ao fazer-se desaparecer a cor negra, praticar-se-ia algo como um inocente genocídio por meios naturais ou auto-assumido. Em um ou dois séculos, diziam, os negros teriam desaparecido, de um modo ou de outro: extermínio físico ou miscigenação. Se no total o percentual não ultrapassasse $11 \%$ de negros, tudo bem. Aliás, por muito tempo se divulgou que este era 0 percentual de nossa população negra. Jamais circulou por aqui o mais elementar conhecimento de genética. A política do embranquecimento foi e é uma piada de muito mau gosto. Sinto-me envergonhado de, como brasileiro, comentála. 0 pior, ou o melhor, a mostrar que não diferimos dos brancos, é que de um modo ou de outro legitimamos a política do embranquecimento: também quisemos embranquecer. 0 processo de alienação não escolhe raça, sexo, credo ou cor.

Com referência à Lei Áurea, até mesmo por elidir a questão da indenização, é nada mais nada menos que um ato político imoral, o mais conspícuo exemplo de 'lei reverenciada, mas que jamais pegou', fato invisível aos olhos míopes da historiografia brasileira, não obstante existir, ainda hoje, nos quadros de nossa Polícia Federal, unidade para o combate à prática da escravização, generalizada nas áreas de latifúndio, de garimpo, de distribuição de droga. Assim, a ainda chamada Lei Áurea, que devia ter sido uma senha para o deslanchar de um conjunto de políticas públicas afirmativas da nacionalidade, simboliza a escamoteação dessa linha de políticas públicas. A atual postulação da questão das cotas deverá ser vista nesta perspectiva.

Jamais seremos um povo, se não pudermos nos olhar nos olhos e declararmos nossas diferenças. Cumpre que se levante, mesmo, a questão do imigrante, aquele que chegou aqui, trabalhou e se caldeou, e aquele que veio trazendo a cor da pele e um 'atestado ideológico' de direita, aqui recebendo terras, sementes e implementos que imediatamente arrendava, alugava ou vendia, indo para as cidades 'casar' com as filhas ou filhos de coronéis. Não se fala aqui dos que vieram nas levas da mineração, dos que vieram porque não tinham opção, pois estes conosco se irmanam e formam esse povo que se quer ver uma nação. Fala-se dos que vieram após os grandes levantes anarquistas do início do século 20, quando os órgãos de imigração, o federal e os estaduais, tornaram-se cativos da direita racista, não mais recebendo visto de entrada 
senão os imigrantes infensos ao ideário progressista. Há muito a se levantar nesta questão. Cumpre saber se há coragem suficiente entre esse pessoal dito acadêmico.

\section{NA AUSÊNCIA DO PACTO}

Chame-se a si mesma de nação, de povo ou o que valha, para Rousseau, numa relação despótica, constituída, de um lado, por uma cadeia de proprietários, chefes ou senhorese, de outro, por uma multidão de servos, escravos, súditos ou o que valha, quadro em que a toda hora, desde sempre, nos reconhecemos, não se pode falar daquilo que $D u$ contrat social define como Povo, Nação, e a justificativa é lídima: aí não há noção nem de 'bem público' nem de 'corpo político'. ${ }^{6}$ As coortes dos PC's Farias e dos Collor's do Brasil que o digam.

Então, como seria em essência uma verdadeira Nação? - De modo diferente do que ocorre na vida real, na hipótese ou no 'querer' de Rousseau, chega-se a um momento em que os obstáculos que dificultam a conservação dos homens em estado de naturezase fazem superiores às forças que esse ou aquele indivíduo possa exercer para continuar nesse estado. É quando se coloca o desafio de "Achar uma forma de associação que defenda e proteja de toda força comum a pessoa e os bens de cada associado, e pela qual cada um ao se unir ao todo, não obedeça senão a si mesmo e continue tão livre quanto antes" ? É quando cumpre elaborar um Pacto.

As cláusulas desse Contrato podem se reduzir a apenas uma: alienação total de cada associado, com todos os seus bens e direitos, à comunidade. Todos e cada um passam a formar uma entidade constituída de partes iguais, mas inseparáveis, em que ninguém poderá dizer que deu mais, portanto merece mais, ou menos, portanto merece menos. Cada qual se dando a todos, não se dá a ninguém, não havendo nenhum associado do qual se retire mais, ou menos, do que se deu de si mesmo. Necessariamente, na assinatura do Pacto, na formação da Nação, "ganha-se o equivalente do que se cedee, ainda, ganhase mais força para que se conserve o que se tem". ${ }^{8}$

Questão nodular no estabelecimento desse pacto é a dos bens reais trazidos do estado de natureza, tornados agora, por um lado, propriedade privada; por outro, coisa pública. Mas entenda-se que a sacralidade ou inviolabilidade da propriedade privada diz

6 J-J Rousseau. Op. cit., p. 23.

Id. ib., p. 24.

${ }^{8}$ Id. ib., p. 25. 
respeito àquela que é compatível com a liberdade individual. É inimaginável o exercício das prerrogativas do ser livre, ou seja, possibilidade de escolha, de disposição de si mesmo e responsabilidade por seus atos, à ausência de meios materiais com que esse homem possa conservar-se vivo para dispor de si, para escolher, para agir com responsabilidade. Esteio da liberdade individual, a propriedade privada não pode se tornar instrumento da escravização do outro. "Pode acontecer que os homens comecem a se unir antes que possuam algo e que, apossando-se em seguida de um terreno suficiente para todos, venham a usufruí-lo em comum ou o dividam entre si, seja igualmente, seja consoante proporções estabelecidas pelo Soberano". 9 Ao que parece, segundo Rousseau, fica legitimada não só a Reforma Agrária, como também a existência da nação ex-colonial, porque a ela, a suas áreas desabitadas, todos chegam sem nada, concluímos.

Soberano é um dos termos pelos quais é referida essa entidade formada pela doação absoluta de homens saídos do estado de natureza. De modo nenhum uma pessoa, Soberano é um corpo moral e político, um ente público que se forma pela união de seres livres que continuam livres; enfim, é a Nação, também referida por Cité (Cidade, donde Cidadania), República (res publica - coisa pública) ou Corpo Político. Essa entidade é também chamada por seus membros de Estado, quando passivo, isto é, no contexto da obediência a suas leis; de Soberano, quando ativo, isto é, formatando e reformatando o ser social; ou de Potência, quando em relação a entidades semelhantes.

Parte de um todo inseparável, na Nação cada indivíduo pode ser visto como um elo a integrar-se por dois outros: de um lado, o Soberano, já que como partícula indivisível do Soberano ele é Soberano em relação a circunstanciais particulares; por outro, o Estado, que é o Soberano em relação às suas leis. Com essa comparação temos o Cidadão, credor de direitos, e devedor de obrigações.

Fora desse modelo rousseauniano, não deveria haver definição para Cidadania, essa palavra que na boca de muitos brasileiros, até mesmo pela ausência de uma origem pactuada para nossa experiência social, tornou-se algo como uma disciplina escolar extracurricular, cuja falaciosa compreensão (o 'conhecer seus direitos') é moeda de curso livre no Brasil neoliberal. 0 objetivo é convencer o excluído de que ele mesmoé o culpado de sua exclusão, não 'cobra' seus direitos, porque mal-educado, de hábitos anti-sociais. Em primeiro lugar, a se seguir Rousseau, cidadania não se ensina. Surgido o Soberano, a Cité, o Estado, surge o Cidadão e sua condição de cidadania. Desse mesmo modo, é absurdo falar em cidadão de primeira e de segunda classes: há pacto ou não há pacto; há 
cidadão ou não há cidadão. É sempre interessante lembrar que ninguém funda 'ong' para ensinar cidadania a ricos. Por que será? Atualmente, ouve-se a toda hora advogados, promotores e juízes falarem em 'cidadão comum'. "Cidadão comum não pode ter arma". Esta categoria não pode existir. Na formação da nação ninguém terá ou teria dado mais do que os demais. Ou há cidadão ou não há cidadão. Num contrato cuja essência seja gerar credor e devedor, ninguém pode ensinar o outro a ser credor ou devedor.

Insista-se que estamos diante de um modelo teórico, uma abstração ideal. A distância entre sua consistência lógica no plano conceitual e no da realidade, deveria nos levar a uma de duas: tentar adequar a realidade, a sociedade, ao modelo, ou superar o modelo, abandonando-0. Censurável é 0 uso que se faça dos elementos do modelo ou de sua lógica interna onde ele jamais tenha sido levado à prática. 0 intenso curso que depois de 1988 se vem dando ao termo cidadania indica que se lhe estão atribuindo significado não só impreciso, mas contraditório, anti-Rousseau, falacioso. Hoje, em harmonia com as teses da democracia participativa, cidadão terá que ser o excluído que luta para incluir-se construindo o contexto de sua inchusão... Mas este é um guerrilheiro, um revolucionário, termos hoje tornados tabus, mas já há muito cunhados na língua.

Retomando a questão da essência da Nação, ressalte-se que a Soberania, que se manifesta como exercício da vontade geral de um povo, é inalienável e indivisivel, e o Soberano, que não é senão um ente coletivo, não pode ser representado a não ser por si mesmo: o poder pode se transmitir, mas de modo nenhum a Vontade. Carece de sentido a, b ou c dizer que está representando a Nação, o Brasil, no caso. 0 Soberano, a nação, através de seus órgãos, no máximo ter-lhe-ia concedido um poder vinculado, ad referendum da Nação. E só. E para evitar qualquer tipo de truísmo na relação de poder entre Soberano e Estado, Rousseau observa que "a deliberação pública que pode obrigar todos os súditos para com o Soberano em função de ambas as relações sob as quais cada um dos particulares é considerado, não pode, por razão contrária, obrigar o Soberano para consigo mesmo (enquanto Estado), e que, por consequiência, écontra a natureza do Corpo Político que o Soberano se imponha uma lei que não possa violar...por onde se vê que não há nem pode haver nenhuma espécie de lei fundamental obrigatória para o Corpo do Povo, nem mesmo o Contrato Social." (p.27). É neste sentido que o Povo é Soberano. Observe-se que aqui estaríamos diante de uma formulação eminentemente ambígua, se se entende Soberano como o segmento social e politicamente hegemônico. No Brasil soberano é o Brasil.

E como era ou é o estado de natureza? - Das proposições básicas até aqui comentadas, faltou fazer algumas explicitações sobre esse conceito, que em Rousseau, de. 
modo contrário a Hobbes, não se traduz por um contexto de guerra interminável de todos contra todos e de cada um contra cada um. 0 estado de natureza se caracterizaria por um contexto social de inocência, portanto de amoralidade, potencialmente idílico ou trágico. Não há noção de propriedade, mas de uma posse contingente, em comunhão inclusive com os animais; quando os homens se defrontam com interesses diferentes, matam e morrem, mas não há noção de guerra, uma relação que, segundo Rousseau - parece que falando diretamente para os 'Bush's' da vida - só pode existir de Estado para Estado, sempre vinculando bens reais, de valor patrimonial, jamais valores pessoais. ${ }^{9}$

Vivendo no estado de natureza sob a determinação dos fatores ambientais, é de se imaginar nesses núcleos humanos a manifestação das forças espirituais da Espécie: 0 Bom Selvagem num Éden de fartura, quadro que, à ocorrência de um desequilíbrio qualquer, transfigurar-se-áem desgraças, privações, lutas de matar e morrer. "A passagem do estado de natureza ao estado civil produz no homem mudanças consideráveis, substituindo em sua conduta o instinto pela justiça e dando às suas ações a moralidade que até então lhe faltava. É somente então que, a voz do dever sucedendo à impulsão física e o direito ao apetite, o homem que até esse momento não tinha olhado senão para si mesmo, vê-se obrigado a agir segundo outros princípios, e a consultar sua razão antes de ouvir suas inclinações. Embora ele se prive, neste estado, de várias vantagens que tinha no estado de natureza, ele ganha outras vantagens maiores, suas faculdades se exercitam e se desenvolvem, suas idéias se estendem, seus sentimentos se enobrecem, sua alma toda inteira se eleva a tal ponto que, se os abusos desta nova condição não o degradassem muitas vezes em níveis abaixo da condição de que ele acaba de sair, o homem devia bendizer sem cessar o instante feliz que de lá o arrancou para sempre, e que, de um animal estúpido e limitado, fez um ser inteligente e um homem". ${ }^{10}$

Como funcionaria o modelo? - Como encontrar a vontade da Nação e como expressá-la? Com os limites de tempo e espaço inerentes a texto dessa natureza, vamos por partes.

9 Id. ib., p. 32.

10 "A guerra não é de modo nenhum uma relação de homem a homem, mas uma relação de Estado para Estado, na qual os particulares não são inimigos senão acidentalmente, de modo nenhum como homens nem mesmo como cidadãos, mas como soldados; não como membros da pátria, mas como seus defensores. Enfim, um Estado não pode ter como inimigos senão outros Estados, de modo nenhum homens, entendido que entre coisas de diversas naturezas não se pode fixar um nexo verdadeiro. J-J Rousseau. Id. ib., p. 21. 


\section{A Generalidade Da LeI}

Com o Pacto confere-se existência ao Corpo Político; com a lei dá-se-lhe movimento, expressando-se sua vontade, uma vez que "0 ato primitivo pelo qual este corpo se forma ese une, nada determina quanto ao que deve fazer para se manter". ${ }^{11}$ Nesse sistema, a questão da generalidade da lei é pedra angular: "Já disse não haver vontade geral sobre um objeto particular. Efetivamente, este objeto particular está dentro do Estado ou fora do Estado. Se está fora, uma vontade que lhe é exterior não é geral em relação a ele mesmo; e se este objeto está dentro do Estado, dele faz parte: então se forma entre o todo e sua parte uma relação que dele faz dois corpos separados, um sendo a parte, e 0 outro, o todo menos essa parte. Mas o todo menos uma parte nãoé mais o todo e, pelo quanto essa relação subsista, não há mais o todo e sim duas partes desiguais: de onde se segue que a vontade de uma não é igualmente geral relativamente a outra". ${ }^{12}$

A matéria sobre a qual se legislaé geral como a vontade que a estatui. "É a este ato que chamo de uma lei". A lei considera (tanto) os sujeitos incorporados (quanto) as ações, como abstratos. "Assim a lei pode estatuir que haverá privilégios, mas ela não os pode conceder nominalmente a uma pessoa; a lei pode fazer várias Classes de Cidadãos, atribuir mesmo as qualidades que darão direito a essas Classes, mas ela não pode nomear tais ou quais para nelas serem admitidos... em uma palavra, toda função que se reporte a um objeto individual não pertence à potência legislativa". ${ }^{13}$ Em coerência com essa definição, será uma Re(s)pública todo Estado regido pela lei como aqui entendida, pois nele só o interesse público governa, e coisa pública é tudo, é toda e qualquer coisa.

Como espécies de leis, fontes do direito, Rousseau nomeia quatro: a) as leis políticas, que regulam as relações do todo com o todo, ou de outro modo, do "Soberano para com 0 Estado"; b) aquelas que regulam as relações dos particulares entre si e com 0 Estado, de onde nascem as leis civis; c) as leis criminais, ou seja, as que sancionam todas as demais, d) e por último, as normas de moralidade, os costumes, a opinião pública.

Cumpre, porém, no modelo, distinguir Lei, de Atos de Magistratura. Se esse coletivo que se forma a partir de doação unitária, um a um, no ato de votar o faz unitariamente, as delta-diferenças então se somam e se anulam, surgindo como resultado a Lei. Mas se no ato de votar o coletivo se divide em partidos, associações etc., as diferenças então

\footnotetext{
${ }^{10}$ Id. ib., p. 29.

"Id. ib., p. 42.

${ }^{12}$ Id. ib., p. 43.

${ }^{13}$ Id. ib., p. 43.
} 
surgem a partir de números de grande magnitude, não mais se podendo falar em Lei, em Vontade Geral, mas em determinação particular, em Decreto, em Ato de Magistratura.

\section{O LegISLADOR E O REPRESENTANTE}

Ente de natureza moral, nascido da total e absoluta doação de todos, a Vontade Geral ou o Soberano só conhece, diante do devir, uma direção: a do bem-estar geral, a da igualdade. Nos quadros da realidade, porém, a marcha em direção ao devir requer a elaboração de mapas, requer batedores, requer até motivos para o caminhar. No plano real, além dessas ausências, contam-se outras limitações à Vontade Geral. "Quer-se sempre o bem-estar, mas nem sempre esse bem-estar é visto. Se por um lado o povo jamais é corrompido, na maioria das vezes é enganado, quando então parece querer o mal" . ${ }^{14}$

Uma passagem de trânsito difícil nesse trabalho do grande Rousseau é a que vai tentar explicar a dinâmica social, o elemento-motor, aquilo que, no que tange à energia na natureza, é a diferença de nível, o que faz a água fluir do nível mais alto para o mais baixo. 'Quê' e 'como' fazer os homens trabalharem? Rousseau nada nos diz explicitamente, mas é aí que entra a Lei, pensamos. À Lei cumpre criar certo nível artificial de desigualdade social, algo como uma 'gincana' para continuarmos nesse ambiente lúdico em que Rousseau nos coloca. Note aqui que não é a primeira vez que se cobre um 'instinto' com o ritual civilizador. Ao comer, devorar, impõe-se o fazer as refeições, jantar, banquetear. Por que não criamos instituições culturais específicas para domar a preguiça, o egoísmo, a usura? Nesse sentido, fica legitimada (se a Lei assim o estatui) a propriedade privada adequada e um quadro hierárquico - a meritocracia. 0 que não aceitam os humanistas é a propriedade como arma para escravizar o outro e as linhas de castas hereditárias: hierarquia baseada em berço, em raça, em cor. Mas essa Lei como tal viria ou virá da Nação, do Soberano, da Vontade Geral.

Fora as imposições contingentes da própria realidade social, no modelo há questões inerentes a sua coerência interna. Já vimos que para Rousseau a soberania não pode alienar-se nem dividir-se, só podendo ser representada por si mesma. Nesse quadro, como ficaria a questão da representação política? Como organizar, como ouvir a Vontade Geral?

Rousseau não resolve esses problemas. Na elaboração de mapas e de rotas ao devir de um povo, ele encarece a necessidade do Legislador, o Iluminado, a ter como parâmetros ontem Licurgo, Sólon, Moisés; hoje diríamos Mao-tse-tung, Nelson Mandela, Fidel Castro, 
eoutros heróis de mesma envergadura. Ageneralizadamente aceitasolução da representação, ele a deriva, como coisa espúria, de indignas práticas feudais. ${ }^{15}$ De modo diferente da visão atual, em que os deputados e senadores, ao receberem o mandato dizem falar em nome da 'Nação', mesmo que tenham como patronos grupos multinacionais, para Rousseau eles não são senão comissários, diríamos "paus mandados", nada podendo concluir definitivamente. "Toute loi que le Peuple en personne n'a pas ratifiée est nulle; ce n'est pas point une loi". 16

As ambigüidades de seu pensamento podem explicar a solução hoje vigente em quase todo mundo, segundo a qual, na formação do Estado-nação, anular-se-iam de modo absoluto (exceção feita para os segmentos excluídos) todas as diferenças entre os membros de uma formação social - nascimento, posses, dons naturais, nível cultural etc. - dando-se aos incluídos o status de cidadão, um santo leigo, ${ }^{17}$ que mesmo sem ter participado de pacto nenhum, é depositário da soberania nacional. A vontade, o querer desse "soberano" se defere a representantes, idealmente eleitos por sufrágio universal, cuja função antes que de só representar, é a de falar e agir em nome da 'nação'. Apontamse entre as fraquezas do modelo: a) vacuidade do conceito de 'cidadão' quando oposto aos homens reais, suporte de marcadas diferenças de natureza sociológica; b) paradoxo da representação, a qual se arroga o poder de falar em nome da nação, mas é estipendiada por grupos empresariais, geralmente multinacionais, a cujos interesses serve; d) a força conjuntural dos grupos extraconstitucionais que atuam no vazio do conceito de cidadão, retirando até mesmo da esfera governamental o poder do Estado. É o quadro que hoje vemos em paroxismo hiperbólico.

15 "Tão logo que o serviço público deixa de ser o principal negócio dos Cidadãos, tão logo eles preferem dispor de suas bolsas antes que de suas pessoas, o Estado está perto de sua ruína. É preciso ir à guerra?, eles pagam uma tropa e ficam em casa; $E$ preciso ir ao Conselho?, eles nomeiam deputados e ficam em casa. À força da preguiça e do dinheiro, eles enfim dispõem de soldados para sobrepor-se à pátria e de representantes para vendê-la". J-J Rousseau. Id. ib., p. 79.

${ }^{16}$ Id. ib., p. 80.

17 "É o homem esclarecido pela razão, desembaraçado dos preconceitos de classe e das preocupações inerentes à sua condição econômica, capaz de formular uma opinião sobre a coisa pública, abstraindo das suas preferências pessoais, em suma uma espécie de santo laico ao qual se concede a qualidade de membro do soberano precisamente porque o seu desinteresse é penhor do uso prudente que fará da sua soberania....". Burdeau, G. A democracia. Lisboa: PEA, s.d. p.20. 


\section{A Constitucionalidade das Leis das Cotas para Negros}

No cinzelamento do arcabouço de nossa específica formação nacional, aqui e ali as ditas elites brasileiras tomam, de Rousseau, esse ou aquele aspecto formal, como é o caso do preâmbulo das nossas recentes constituições que, em função até das deficiências do instituto da representação, não são nem jamais poderão pretender ser o Pacto. No caso do Brasil, seria mais apropriado dizer que as elites, sem qualquer espécie de pejo, tomam por parâmetro ninguém mais que Karl Marx, quando nos ensina que numa sociedade de classes, a função do Estado é promover a organização social, política e econômica de uma classe às expensas das demais. E uma vez que no Brasil as classes, quando polarizadas, têm cor, vê-se formada a base para a constituição do grande contencioso nacional representado pela constitucionalidade da lei das cotas.

Para grande número de advogados, vez por outra deslastrados em função das nossas constantes entradas nos desvios ou porões da ilegalidade institucional, mas sempre míopes em relação às nossas deformações de nascença, essas peças legislativas são inconstitucionais, já que ferem de pronto o princípio da generalidade das leis. Fazem tal afirmação amparando-se principalmente nos ensinamentos de Rousseau, por um lado esquecendo que não constituímos o modelo de nação por ele prefigurado; por outro, fazendo vistas grossas às centenas de leis particulares (o que em qualquer modelo devia ser um contra-senso) que têm abrigo no direito positivo brasileiro: privilégios para descendentes de nossa discutível nobreza, até pouco tempo "bibelôs mensais de milhares de reais para filhas de oficiais das forças armadas, das polícias, em muitos Estados para as esposas de juízes, desembargadores etc. No lado puramente econômico, perdão de dívidas, de juros, ou incentivos fiscais não só a esse ou àquele segmento, mas a essa e àquela empresa ou pessoa. Que nada seja falado sobre as leis específicas que concedem privilégios a membros da ex-família reinante, nem das inovações da atual Constituição com relação à múltipla nacionalidade. Um aríete em nossa muralha. Que jamais se fale em privilégios a essa ou àquela etnia ou em distribuição de terras: que jamais se fale nos recentes episódios da concessão de terras em Mato Grosso do Sul para plantadores de soja 'gaúchos' que 'ainda' não sabiam falar português. O fato está aí, vergonhoso!

E que não se fale também das 'cotas' que sempre existiram privilegiando os ricos ou seja, os brancos, dado o fato de que aqui a pobreza é levada a ter cor. Também não falemos em certas corporações militares cujos altos escalões, ainda nos anos 1990, eram categoricamente vedados aos negros. Não se fale na magistratura. Não se fale no setor acadêmico de modo geral, em carreiras como medicina, desenho 
industrial, comunicação. Mas fale-se, e fale-se muito em pedagogia, serviço social, letras, que, a continuarem como estão, poderão vir a ser áreas acadêmicas repudiadas pelos brancos ricos, ou melhor, já são.

Apresentado aqui como elementos para que brancos e negros nos conheçamos melhor, reflita-se sobre o fato de que as elites norte-americanas, até mesmo para alardearem que são 'ungidas pela graça divina', jamais matriculariam os filhos numa universidade pública, principalmente essas nas áreas de grande concentração afro-ibérica: Nova York, Washington etc. Aqui, pessoas de posses vão a restaurantes populares, tomam de assaltos os colégios de aplicação públicos, assenhoreiam-se dos cursos universitários cujos diplomas conferem status, desde que da universidade pública, sem que jamais se vejam tais fatos como uma lei de cotas às avessas. À medida que marcha essa situação absurda, a universidade privada deverá apoiar qual quer tipo de ação afirmativa, pois corre o risco de vir a não ter mercado... Ou a bizarria paradoxal: aqui o negro pobre vai para a universidade privada, cara e de baixa qualidade, e o rico vai para a pública, gratuita, de alta qualidade.

Lembre-se que fora do modelo rousseauniano, carece de amparo ético, portanto político no seu sentido verdadeiro, a referência ao princípio da generalidade das leis no que tange aos diplomas em pauta. Imperfeitos quanto possam estar, já que são dois diplomas, de propósito sancionados para que um inviabilizasse o outro, eles nos sinalizam quanto às imperfeições do nosso 'acochambramento' social, na medida em que no contexto da violência urbana e rural, no contexto da fome, do desemprego, da ressurgência da escravidão, no contexto do multimilionário negócio da droga, um iceberg em que, apenas em certas cidades, a cabeça é negra, enfim, no contexto da discriminação racial, do genocídio étnico e cultural, essas leis nos convidam à releitura de Do contrato social para que vejamos quão perdidos estamos, não nos descaminhos do estado de natureza, mas no da Barbárie. É chato ser brasileiro assim. 